\title{
Type1 Interferons Potential Initiating Factors Linking Skin Wounds With Psoriasis Pathogenesis
}

\author{
Ling-juan Zhang ${ }^{1,2 *}$ \\ 'School of Pharmaceutical Sciences, Xiamen University, Xiamen, China, ${ }^{2}$ Department of Dermatology, University of \\ California, San Diego, La Jolla, CA, United States
}

Psoriasis is a chronic autoimmune skin disease that can often be triggered upon skin injury, known as Koebner phenomenon. Type 1 interferons (IFN $\alpha$ and IFN $\beta$ ), key cytokines that activate autoimmunity during viral infection, have been suggested to play an indispensable role in initiating psoriasis during skin injury. Type 1 IFN-inducible gene signature has been identified as one of the major upregulated gene signatures in psoriatic skin. Type 1 IFNs treatments often directly induce or exacerbate psoriasis, whereas blocking type 1 IFNs signaling pathway in animal models effectively inhibits the development of T cell-mediated skin inflammation and psoriasis-like inflammatory diseases. Epidermal keratinocytes (KCs) occupy the outermost position in the skin and

OPEN ACCESS

Edited by:

Teruki Dainichi,

Kyoto University, Japan

Reviewed by:

Kristina Seiffert-Sinha, University at Buffalo, United States Kelly Nordyke Messingham, The University of lowa, United States

*Correspondence:

Ling-juan Zhang

lingjuan.zhang@xmu.edu.cn

Specialty section:

This article was submitted to Immunological Tolerance and Regulation,

a section of the journal

Frontiers in Immunology

Received: 28 February 2019 Accepted: 07 June 2019 Published: 25 June 2019

Citation:

Zhang L (2019) Type1 Interferons Potential Initiating Factors Linking Skin Wounds With Psoriasis Pathogenesis.

Front. Immunol. 10:1440.

doi: 10.3389/fimmu.2019.01440 are the first responder to skin injury. Skin injury rapidly induces IFN $\beta$ from KCs and IFN $\alpha$ from dermal plasmacytoid dendritic cells (pDCs) through distinct mechanisms. Host antimicrobial peptide LL37 potentiates double-stranded RNA (dsRNA) immune pathways in keratinocytes and single-stranded RNA or DNA pathways in pDCs, leading to production of distinct type $1 \mathrm{IFN}$ genes. IFN $\beta$ from KC promotes dendritic cell maturation and the subsequent $\mathrm{T}$ cell proliferation, contributing to autoimmune activation during skin injury and psoriasis pathogenesis. Accumulating evidences have indicated an important role of this dsRNA immune pathway in psoriasis pathogenesis. Together, this review describes how skin injury induces type 1 IFNs from skin cells and how this may initiate autoimmune cascades that trigger psoriasis. Targeting keratinocytes or type 1 IFNs in combination with $T$ cell therapy may result in more sustainable effect to treat auto-inflammatory skin diseases such as psoriasis.

Keywords: type 1 interferons, interferon beta, innate immunity, keratinocytes, inflammation, skin wounds, psoriasis

\section{INTRODUCTION}

Skin, the largest organ of human body, functions as a physical and immunological barrier to protect our bodies from external threats. The epidermis, positioned at the front line of defense, has evolved to provide rapid and specific innate immune response that shapes the adaptive immune response, leading to immediate as well as long term protection against physical dangers $(1,2)$. The barrier function of epidermis is primarily provided by keratinocytes (KCs), the pre-dominant epidermal cell type. While the physical barrier of the skin is maintained by a tightly controlled balance between proliferation and differentiation of KCs $(3,4)$, the immunological barrier function of epidermis 
relies on rapid, precise and situation-specific innate immune responses of KCs to insults. Psoriasis is considered as a T cellmediated autoimmune skin disease, whereas the role of KCs in initiating the early upstream events in psoriasis has been underappreciated. In this review, we review current understanding of immunopathology of psoriasis, the role of keratinocytes in psoriasis initiation, and then emphasize on the role of type 1 IFNs in linking innate immune activation upon skin injury and the subsequent autoimmune amplification that leads to psoriasis.

\section{PSORIASIS: ETIOLOGY, IMMUNOPATHOGENESIS AND THERAPIES}

Psoriasis is a chronic autoimmune skin disorder characterized by well-demarcated, raised areas of erythematous plaques, often covered by silvery scaling (5). It is estimated that psoriasis affects 125 million people worldwide $(\sim 1.7 \%$ of the world population), including $2 \sim 4 \%$ of the US or European populations and $\sim 0.5 \%$ of the Asians (6). The three principal histological features of psoriasis are hyperplastic/thickened epidermis, elongated and increased vascularity in the dermis, and inflammatory leukocyte infiltration (5). Beyond the lesions, psoriasis is also associated with several comorbidities, such as rheumatoid arthritis, atherosclerosis, cardiovascular diseases, obesity, type 2 diabetics, Alzheimer's disease, depression, and non-melanoma skin cancer $(7,8)$. Increased disease burden greatly impairs the quality of life in psoriasis patients. A better understanding of psoriasis pathophysiology will help to decipher the molecular alliance of psoriasis with its comorbidities.

The etiology of psoriasis remains obscure. As shown in Figure 1, besides genetic factors, several triggering factors have been linked with an exacerbation of psoriasis, such as infection, wound, obesity, stress, and drugs including betablockers, lithium, interferons, and imiquimod (9-11). Innate immune responses of resident keratinocytes or infiltrated plasmacytoid dendritic cells ( $\mathrm{pDCs}$ ) are believed to play a critical role in initiating the subsequent adaptive immune events including dendritic cell (DC) maturation and $\mathrm{T}$ cell activation $(2,12,13)$. It has been shown that keratinocyte or pDCs derived cytokines, such as IL1 $\beta$ and type 1 IFNs, activate DC, which then stay local or travel to lymph nodes and secrete cytokines TNFo, interleukin (IL)-12 and IL23, leading to type $1 \mathrm{~T}$ helper (Th1), and type $17 \mathrm{~T}$ helper (Th17) cell activation, respectively $(2,14)$. Activated $\mathrm{T}$ cells accumulate at the affected skin area, releasing additional cytokines, such as IFN $\gamma$, TNF $\alpha$, IL-22, and IL-17A (15). These $\mathrm{T}$ cell derived cytokines recruit additional immune cells and boost keratinocyte activation, leading to the initiation of a self-propelled cycle of auto-inflammation and the ultimately uncontrolled keratinocyte hyperproliferation and psoriatic plaque formation $(16,17)$.

Preventing immune activation is the key to treat psoriasis. Conventional psoriasis therapies, including general immunosuppressive therapies (such as topical corticosteroids and systemic methotrexate or cyclosporin therapies), vitamin D analogs, topical retinoids, and UVB phototherapy, are associated with broadband immunosuppression and/or organ toxicities that can be problematic when used long term (18). New biological drugs against specific immunological elements have gained popularity as safe and effective alternatives to treat moderate to severe plaque psoriasis. These biological drugs including monoclonal antibodies against TNF $\alpha$ (such as etanercept and infliximab), IL12 (such as Ustekinumab), IL23 (such as Guselkumab and Tildrakizumab), IL-17A (such as Secukinumab and Ixekizumab), or IL17AR (such as Brodalumab) have shown clinical efficacy in improving skin conditions in clinical trials and most of these drug are already on the market $(9,19-21)$. However, relapse of the disease shortly after drug withdrawal is one of the major obstacles for these DC or T-cell targeted therapies in clinical trials (22-25), suggesting that preventing adaptive immune activation alone is not sufficient to treat psoriasis. A better understanding of the innate immune mechanisms initiating psoriasis is urgently needed to develop novel therapeutic approach to treat psoriasis.

\section{KOEBNER PHENOMENON, FROM SKIN WOUND TO PSORIASIS}

The initial onset of psoriasis is often followed by chronic relapses of the disease triggered by wounding, infections and mechanical stress (5). In 1876, Hinrich Koebner, MD, first described the development of psoriatic lesion after physical trauma such as tattoos, horse bites, and wounds. Later, "Koebner phenomenon" has been used to describe the formation of isomorphic lesions on healthy skin following a cutaneous trauma (e.g., wounds, burns, or surgical incisions) and it is now not restricted to psoriasis but applies to many other skin conditions, such as lichen planus, vitiligo, and lupus erythematosus. Dermal pDCs, a rare population of circulating cells specialized in the production of type 1 IFNs, is thought to be one of the earliest events in psoriasis pathogenesis and subsequently primes the innate and adaptive immune system $(12,26)$. While dermal pDC activation in wounded skin may partially explain Koebner phenomenon, it is still unclear why even superficial tattoos can trigger the pathogenesis of psoriasis. An epidermal mechanism is likely to play a role in the development of a Koebner reaction in psoriatic patient.

\section{KERATINOCYTES UNDER FIRE OF PROINFLAMMATORY CYTOKINES}

Keratinocytes, constituting $\sim 90 \%$ of the epidermal cells, are poised directly at the interface with the external environment, depositing them as the first responder to skin injury. Recent studies have established the essential role of keratinocytes in psoriasis initiation. Rapid innate immune responses of keratinocytes, to a variety of external stimuli, leads to production of an array of pro-inflammatory 


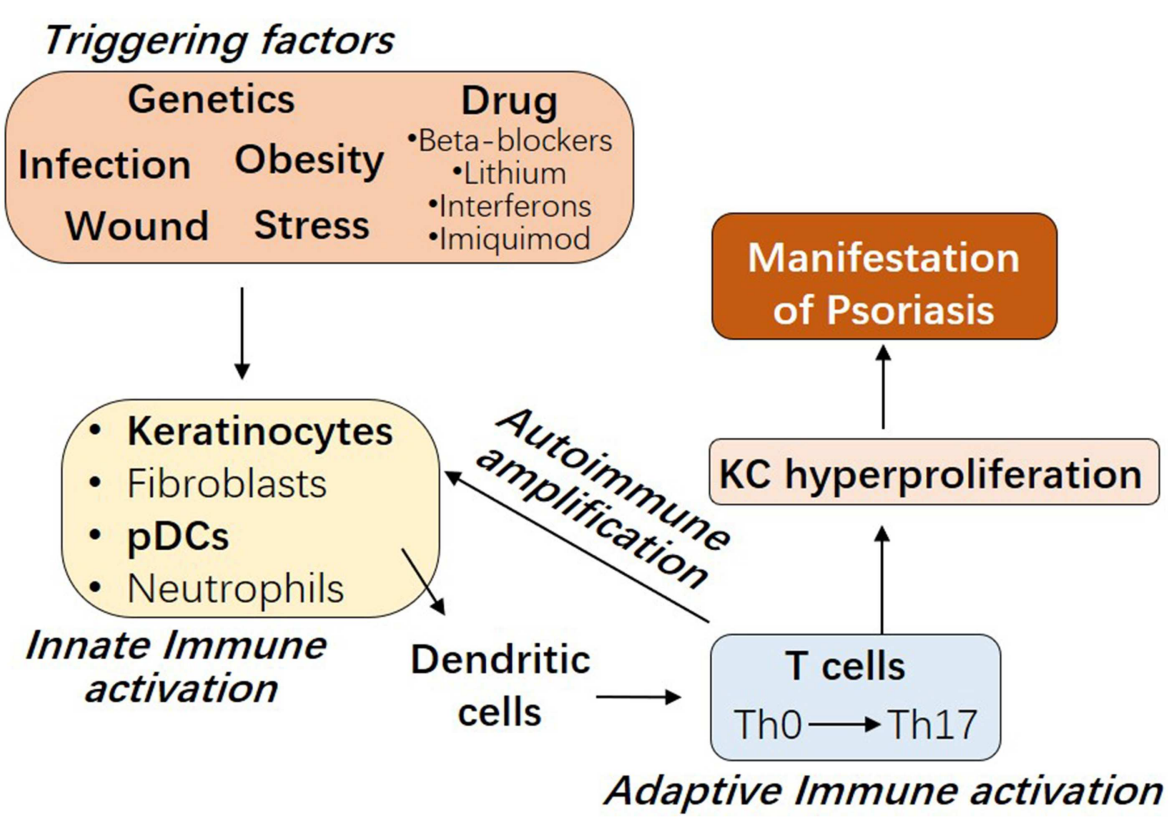

FIGURE 1 | The interplay between innate and adaptive immune cells in the pathogenesis of Psoriasis. Psoriasis can be triggered by several factors, including genetic variants, infection, wound, obesity, stress, and drugs. Early upstream events in psoriasis involve the innate immune activation of skin resident keratinocytes or fibroblasts or recruited plasmacytoid dendritic cells (pDCs) or neutrophils. Cytokines derived from these innate immune cells promote myeloid dendritic cell maturation, with consequent Th17 T cell development and the beginning of the adaptive immune phase. T cell infiltrate promotes inflammatory amplification of innate immune cells, leading to the formation of an autoimmune self-amplifying loop that drives pathogenic hyperproliferation of keratinocytes and manifestations of psoriasis.

cytokines or chemokines such as IFN $\beta$, IL1 $\beta$, IL36, TNF, IL6, IL8, IL25, and CXCL10 (2, 27-29). These keratinocyte-derived cytokines prime epidermal innate immune signals with dermal adaptive immune system, contributing to autoimmune activation and psoriasis pathogenesis $(2,3,27,28,30,31)$.

The inflammatory $\mathrm{T}$ cell phenotype of psoriasis can be initiated by altering innate immune system of keratinocytes in mice. For example, epidermal specific deletion of IKK2 (inhibitor of nuclear factor $\kappa \mathrm{B}$ ) (32) or c-JUN (33) or epidermal specific overexpression of Tie2 (34) or IL17C (35) or the active form of STAT3 (36) or IL25 (29) lead to spontaneous keratinocyte activation and cytokine release followed by the development of psoriasis-like skin inflammation. Recent study from Kabashima's group shows that conditional deletion of TRAF6 in keratinocytes abrogates DC activation, IL-23 production, and the subsequent IL-17 mediated psoriatic inflammation in the imiquimod psoriasis mouse model (37). Our group have found that induction of IFN $\beta$ from $\mathrm{KC}$ is one of the earliest innate immune events during skin injury (2). Keratinocyte-derived IFN $\beta$ promotes dendritic cell maturation and the subsequent $\mathrm{T}$ cell proliferation, leading to psoriatic inflammation development (2). These studies suggest that innate immune responses of keratinocytes are essential to initiate the autoimmune cascade and drive psoriasis pathogenesis, and type 1 IFNs may function as an early initiating factor linking skin wounds with adaptive immune activation that drives psoriasis.

\section{TYPE 1 IFNS AND} AUTOIMMUNE DISEASES

Type 1 interferons (IFNs) belong to the class II family of cytokines, which is composed of 16 members, including 13 IFN $\alpha$ subtypes, IFN $\beta$, IFN $\varepsilon$, IFNא, and IFN $\omega$ (38). Among these type 1 IFNs, IFN $\alpha$, and IFN $\beta$ are the most extensively studied. Type1 IFNs were first discovered more than 60 years ago as the key factors induced upon viral infection, owing to their ability to limit viral replication and promote immune activation (39-41). And now type 1 IFNs have been recognized as the central cytokines that link innate immunity with autoimmune activation during pathogenesis of several systemic autoimmune diseases and several organ-targeted inflammatory diseases (42, 43). Systemic lupus erythematosus (SLE) is the most well-studied autoimmune disease driven by type1 IFNs (42), and recent studies have also demonstrated pathogenic role of type 1 IFN in psoriasis, rheumatoid arthritis, diabetes mellitus, Sjogrens syndrome, dermatomyositis (DM), and systemic sclerosis (38, 44-46). SLE and psoriasis share many similar clinical features and can both be triggered by infection, wounding or type1 IFNs, and Th17 T cells contribute to pathogenesis of both diseases. However, SLE is characterized by overproduction of a wide array of autoantibodies and is therefore traditionally classified as a "B-cell disease" (47), whereas B cell contribution to psoriasis remains unclear. Distinct susceptible genes have been identified for SLE and psoriasis $(6,48)$, suggesting that genetic factors may contribute differential adaptive immune development in 
response to type 1 IFNs, leading to distinct disease manifestation in SLE and psoriasis.

\section{TYPE 1 IFNS AND PSORIASIS PATHOGENESIS}

Type 1 IFNs are associated with psoriasis. Psoriasis is often triggered by chronic viral infections or wounding, and type 1 IFNs as the key cytokines induced upon these conditions (49, 50). Clinically, type 1 IFNs treatments in patients with viral infection or multiple sclerosis (MS) often directly induce or exacerbate psoriasis or psoriasis arthritis (50-53). Furthermore, transcriptome analyses have identified type 1 IFN pathway genes as one of the top upregulated gene signatures in psoriatic skin, outscoring the upregulation of TNF $\alpha$ pathway gene signature (54-56). Immunostaining analyses have shown that while IFN $\alpha$ is pre-dominantly produced by dermal infiltrated pDCs, IFN $\beta$ expression is rapidly induced in epidermal keratinocytes as early as 1 day post-wounding and in psoriatic epidermis compared to normal human skin $(2,12,13)$.

In line with these clinical observations, type 1 IFN pathway is also necessary for the development of $\mathrm{T}$ cell-mediated skin inflammation and psoriasis-like inflammatory diseases in mice. Mice treated with IFN $\alpha$ or IFN $\beta$ neutralizing antibodies, or mice lacking IFNAR (receptor for IFN $\alpha / \beta$ ) failed to develop Th17 cell-mediated skin inflammation $(12,13)$. Fuchs's group shows that UV alleviates the imiquimod (IMQ)-induced psoriatic inflammation by downregulating IFNAR1 expression in keratinocytes (57). IMQ-induced psoriatic inflammation was blocked in Ifnar deficient (Ifnar ${ }^{-/}$) mice, and in contrast Ifnar ${ }^{S A}$ mice (in which Ifnar ubiquitination and degradation was blocked) exhibited exacerbated inflammatory response to IMQ compared to wildtype controls (57), demonstrating that IFNAR plays a critical role in promoting the development of psoriasis like inflammation in mice. In addition, mice deficient for interferon regulatory factor 2 ( $\operatorname{Irf} 2)$, the transcriptional attenuator of IFN $\alpha / \beta$ signaling, developed spontaneous psoriasislike inflammatory disease (58). Type 1 IFNs upregulates the expression of IL22 receptor in keratinocytes, leading to an increase in keratinocytes' responsiveness to IL22, which drives Stat3 phosphorylation and keratinocyte hyperproliferation (15). Our group has also shown that IFN $\beta$ from activated human or mouse keratinocytes can directly promote $\mathrm{cDC}$ (conventional dendritic cell) maturation and the subsequent $\mathrm{T}$ cell proliferation in vitro (2). These collective evidences support that type 1 IFNs play an essential role in initiating skin inflammation during psoriasis pathogenesis.

In addition to its proinflammatory role, type 1 IFNs may also regulate keratinocyte differentiation. In both normal and psoriatic skin epidermis, IFN $\beta$ expression is restricted to KCs at the differentiated cell layers $(2,59,60)$, and IFN $\beta$ is expressed by growth arrested or differentiated KCs but not by dividing KCs in vitro (59). Neutralizing IFN $\beta$ in culture medium inhibited differentiation, but addition of exogenous IFN $\beta$ did not stimulate differentiation or alter proliferation (59). Future studies are still needed to determine whether IFN $\beta$ expression in differentiated
$\mathrm{KCs}$ is a consequence or the cause of $\mathrm{KC}$ cell arrest and/or differentiation, and to determine whether IFN $\beta$ contributes to the aberrant proliferation and differentiation in psoriasis.

\section{DISTINCT CELLULAR SOURCE OF IFN $\alpha$ AND IFN $\beta$ IN PSORIASIS}

IFN $\alpha$ and IFN $\beta$ are produced by distinct cellular sources in wounded and/or psoriatic skin. Upon skin injury, pDCs rapidly infiltrate the skin, sense nucleic acid released from damaged cells, then produce large quantity of IFN $\alpha$, which then initiates the autoimmune cascade $(12,13)$ (Figure 2). Activation of pDC precedes $\mathrm{CDC}$ or $\mathrm{T}$ cells activation (12), suggesting IFN $\alpha$ from pDC may play a role during early phase of disease progression. Our group has shown that while IFN $\alpha$ is primarily produced by $\mathrm{pDC}$ in the dermis, IFN $\beta$ is pre-dominantly produced by epidermal keratinocytes in skin wounds or psoriasis (2). Direct comparison of in vitro activated KCs and $\mathrm{pDCs}$ revealed that while KCs lack the ability to produce IFN $\alpha$ upon activation, activated KCs produce higher amount of IFN $\beta$ compared to activated pDCs (2). Secretion of IFN $\beta$ from keratinocytes promotes activation and maturation of classical dendritic cells, leading to the subsequent $\mathrm{T}$ cell proliferation and autoimmune amplification (2). Furthermore, keratinocyte-derived IFN $\beta$ can also promote $\mathrm{pDC}$ maturation and activation (2), suggesting that keratinocytes might also contribute to $\mathrm{pDC}$ activation during early phase of skin injury. Together, these findings suggest that KCs are an active source of IFN $\beta$ and can participate with $\mathrm{pDCs}$ to prime the adaptive immune system during psoriasis pathogenesis (Figure 2).

\section{REGULATION OF TYPE1 IFNS EXPRESSION BY PATTERN RECOGNITION RECEPTORS}

Type 1 IFNs are known to be induced by a variety of DAMPs (damage associated molecular patterns) or PAMPs (pathogen associated molecular patterns) in either through Tolllike receptor (TLR)-dependent or TLR-independent pathways $(38,61)$ in a cell type specific manner. Type1 IFNs can be induced upon activation of endosomal TLR7 and 9 or cytosolic cGASSTING (cyclic GMP-AMP synthase-stimulator of interferon genes) by host or viral or bacterial DNA, endosomal TLR8 by ssRNA, endosomal TLR3 or mitochondrial RIG1 (retinoic acid-inducible gene 1) -MAVS (mitochondrial antiviral-signaling protein) by host or viral dsRNA, or plasma membrane TLR4 by bacterial LPS $(38,61)$. The cell responsiveness to various DAMPs or PAMPs relies on the expression of pattern recognition receptors (PRRs). pDCs express high levels of TLR7 and TLR9, therefore $\mathrm{pDC}$ can rapidly sense self-DNA released upon injury then produce IFN $\alpha(13,26,39)$. While TLR4 and TLR8 are usually not expressed in pDC, these PRRs are highly expressed in classical DC or monocytes (62), making these cells highly responsive to bacterial LPS or self-RNA. In contrast to these myeloid derived immune cells, keratinocytes express high levels of TLR3 and MAVS, but not TLR4, 7, 8, or $9(2,30,31)$. 


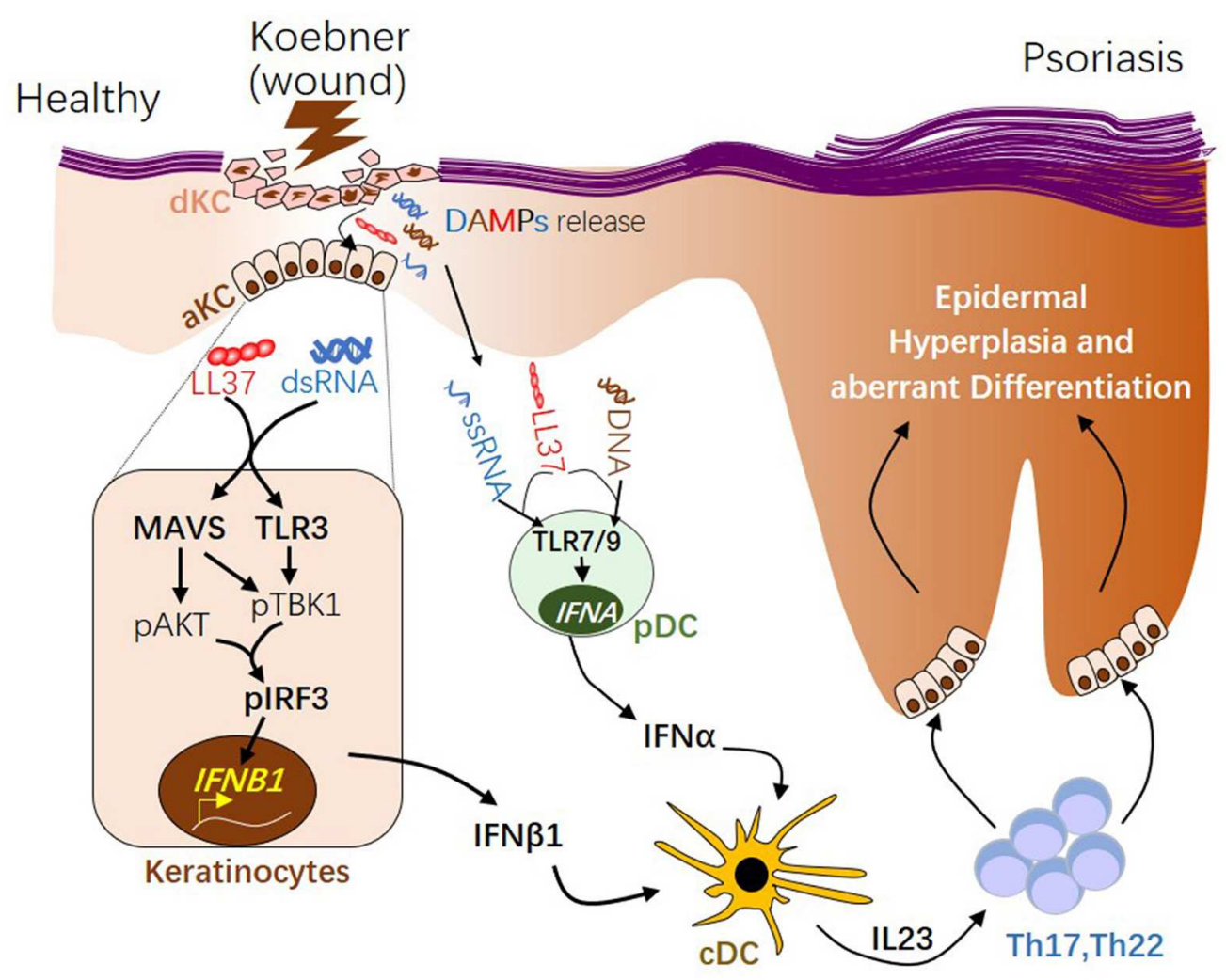

FIGURE 2 | The role of type 1 interferons in initiating psoriatic inflammation during skin injury. During skin injury (known as Koebner phenomenon), damaged keratinocytes (dKC) release self-nucleic acids, including dsRNA, ssRNA, and DNA. Antimicrobial peptide LL37, which is transiently induced in KC upon wounding enables dsRNA recognition by MAVS and TLR3 in KC, leading to activation of the pAKT-pTBK1-pIRF3 signaling cascade and the subsequent transcription initiation of the IFNB1 gene from activated KCs (aKC). LL37 can also enables ssRNA or DNA recognition by TLR7 or 9 in pDCs, leading to transcription of IFNA family genes. Type 1 IFNs, including IFN $\beta$ from KC and IFN $\alpha$ from pDCs, promote maturation of conventional DCs (cDCs). Activated DCs produce IL23, promoting the development of Th17 and Th22 autoimmune T cells, which in turn act on keratinocytes, leading to epidermal hyperplasia and psoriasis pathogenesis. dsRNA, double-stranded RNA; ssRNA, single-stranded RNA; MAVS, Mitochondrial Antiviral Signaling Protein; TBK1, TANK-Binding Kinase 1; IRF3, interferon regulatory factor 3.

Therefore, keratinocytes rapidly produce IFN $\beta$ in response to dsRNA but not to TLR4, 7, 8, or 9 ligands (2). We have showed that, wounded keratinocytes upregulate the expression of antimicrobial peptide LL37, which then enables MAVS and TLR3 in keratinocytes to recognize dsRNA released from dying cells (2). By MAVS-dependent activation of TBK1 (TANKBinding Kinase 1)-AKT (AKT serine/threonine kinase 1)-IRF3 (interferon regulatory factor 3 ) signaling pathway, keratinocytes produce and secrete IFN $\beta$ (2). Keratinocyte-derived IFN $\beta$ then promotes DC maturation and the subsequent $\mathrm{T}$ cell activation to facilitate the development of an autoimmune cutaneous inflammatory response (2). These results show that the cell type specific expression of pattern recognition receptors shape the unique and situation specific innate immune response of these cells.

\section{ROLE OF DSRNA SIGNALING IN PSORIASIS PATHOGENESIS}

Recent studies have suggested an important role for dsRNA in autoimmune initiation during psoriasis pathogenesis.
Extracellular RNA complexes have been found in psoriatic skin (62), and dsRNA is also detected in the cytosol of wounded or psoriatic KCs while it is normally localized in the nucleus of KCs in normal skin (2). Recently, it has been shown that the dsRNA accumulation in psoriatic keratinocytes is associated with impaired A-to-I RNA editing activity, which is essential for post-translational modification of dsRNA and unwinding of dsRNA structures (63). In line with these observations, functional analysis of the psoriasis susceptible gene implicates the involvement of innate immune responses to dsRNA in disease progression (64).

Accumulating evidences have demonstrated that dsRNA can be released as a DAMP by damaged cells or a PAMP by invading viruses to initiate host immune activation. We and others have shown that dsRNA released by tissue damage activates and TLR3 and it is required for normal inflammation or skin regeneration $(30,65)$. Viral dsRNA or endogenous dsRNA (such as U1 RNA) released upon injury acts on keratinocytes through the mitochondrial MAVS pathway to produce IFN $\beta$, leading to adaptive immune activation $(2,31,66)$. Skin injury or infection strongly induces the expression of cathelicidin antimicrobial peptide expression in KCs $(2,67)$, and LL37 (the $\alpha$-helical 
polypeptide derived from cathelicidin) forms pro-inflammatory nanocrystalline complex with dsRNA that potentiates pattern recognition receptor clustering and immune amplification (2, 68). Together these recent evidences have shown that dsRNA released upon infection or injury may synergize with the host antimicrobial peptide to initiate the autoimmune activation in psoriasis, and this dsRNA immune response in keratinocytes may explain the Koebner phenomenon and why viral infection and wounding triggers psoriasis.

\section{TARGETED THERAPIES FOR PSORIASIS: CURRENT STATUS AND FUTURE DEVELOPMENTS}

Psoriasis is not just a $\mathrm{T}$ cell mediated disease. New biological drugs targeting the TNF/IL-23/IL-17 pathways have shown to be safe and efficacious in recent psoriasis clinical trials $(9,19,20)$. However, potential problems including lack of long term efficacy and rapid regain of psoriasis upon drug removal $(22,23,25)$ suggest that inhibiting $\mathrm{T}$ cell activation is only effective to alleviate the disease symptoms but it cannot cure the disease. If the initiating factors such as type 1 IFNs are still active, and these factors can quickly re-initiate the inflammatory cascade and reactivate pathogenic $\mathrm{T}$ cells upon withdrawal of the $\mathrm{T}$ cell targeted therapy. In addition, studies has suggested that cytokines including type 1 IFNs, TNF, and IL17, are interwoven, and each of these cytokines is the cornerstones of an inflammatory triangle that drives the development and maintenance of psoriasis (69). Targeting one of these cytokines may affect the others. For example, patents treated with TNF blocking agents sometimes develop paradoxical psoriasis and this is resulted from an overproduction of IFN $\alpha$ from pDCs upon TNF inhibition (7072). Together, these clinical observations indicate that inhibiting activation of the innate immune system of KCs or pDCs that initiates the autoimmune cascade may be needed in addition to targeted $\mathrm{T}$ cell therapy to prevent reoccurrence of the disease upon drug withdrawal. Targeting MAVS orTLR3 in KC to prevent

\section{REFERENCES}

1. Gallo RL, Hooper LV. Epithelial antimicrobial defence of the skin and intestine. Nat Rev Immunol. (2012) 12:503-16. doi: 10.1038/nri3228

2. Zhang LJ, Sen GL, Ward NL, Johnston A, Chun K, Chen Y, et al. Antimicrobial peptide LL37 and MAVS signaling drive interferon-beta production by epidermal keratinocytes during skin injury. Immunity. (2016) 45:119-30. doi: 10.1016/j.immuni.2016.06.021

3. Wang Z, Zhang LJ, Guha G, Li S, Kyrylkova K, Kioussi C, et al. Selective ablation of Ctip2/Bcl11b in epidermal keratinocytes triggers atopic dermatitislike skin inflammatory responses in adult mice. PLoS ONE. (2012) 7:e51262. doi: 10.1371/journal.pone.0051262

4. Zhang LJ, Bhattacharya S, Leid M, Ganguli-Indra G, Indra AK. Ctip2 is a dynamic regulator of epidermal proliferation and differentiation by integrating EGFR and Notch signaling. J Cell Sci. (2012) 125:5733-44. doi: 10.1242/jcs.108969

5. Griffiths CE, Barker JN. Pathogenesis and clinical features of psoriasis. Lancet. (2007) 370:263-71. doi: 10.1016/S0140-6736(07)61128-3

6. Yin X, Low HQ, Wang L, Li Y, Ellinghaus E, Han J, et al. Genomewide meta-analysis identifies multiple novel associations and ethnic
IFN $\beta$ production from the skin epidermis is of great potential for future targeted therapy development to treat psoriasis.

\section{CONCLUSION}

Located at the skin surface, keratinocytes are constantly exposed to a variety of stimuli, and can secrete an array of cytokines, which function as secondary messengers connecting the innate immune with adaptive immune system. Type 1 IFNs, which are the essential mediator of autoimmunity and antivirus host defense, have emerged as an important initiating element in the immunopathology of autoimmune cascade and psoriasis. In contrast to dermal $\mathrm{pDC}$ which produce IFN $\alpha$ in response to ssRNA or DNA, keratinocytes express high levels of MAVS and TLR3 and therefore can sense self-dsRNA in the presence of antimicrobial peptide and to produce IFN $\beta$. Production of Type 1 IFNs from these innate immune cells upon skin injury may explain the Koebner phenomenon, and this may also explain psoriasis triggered by other factors such as bacterial or viral infections as RNA or DNA released from pathogens will activate similar innate immune response. Future studies will be needed to develop targeted therapy to block the innate immune activation of these PRRs in keratinocytes, which may result in more sustainable interventions to treat psoriasis in addition to current $\mathrm{T}$ cell targeted therapies.

\section{AUTHOR CONTRIBUTIONS}

The author confirms being the sole contributor of this work and has approved it for publication.

\section{FUNDING}

This work was supported by startup funding from Xiamen University (grant: X2123303) from China and National Institute of Arthritis and Musculoskeletal and Skin Diseases grant (R01AR069653) from US. heterogeneity of psoriasis susceptibility. Nat Commun. (2015) 6:6916. doi: $10.1038 /$ ncomms7916

7. Sundarrajan S, Arumugam M. Comorbidities of psoriasis - exploring the links by network approach. PLoS ONE. (2016) 11:e0149175. doi: 10.1371/journal.pone.0149175

8. Saleem MD, Kesty C, Feldman SR. Relative versus absolute risk of comorbidities in patients with psoriasis. J Am Acad Dermatol. (2017) 76:5317. doi: 10.1016/j.jaad.2016.11.037

9. Conrad C, Gilliet M. Psoriasis: from pathogenesis to targeted therapies. Clin Rev Allergy Immunol. (2018) 54:102-13. doi: 10.1007/s12016-018-8668-1

10. Balak DM, Hajdarbegovic E. Drug-induced psoriasis: clinical perspectives. Psoriasis. (2017) 7:87-94. doi: 10.2147/PTT.S126727

11. La Mantia L, Capsoni F. Psoriasis during interferon beta treatment for multiple sclerosis. Neurol Sci. (2010) 31:337-9. doi: 10.1007/s10072-009-0184-x

12. Nestle FO, Conrad C, Tun-Kyi A, Homey B, Gombert M, Boyman O, et al. Plasmacytoid predendritic cells initiate psoriasis through interferon-alpha production. J Exp Med. (2005) 202:135-43. doi: 10.1084/jem.20050500

13. Gregorio J, Meller S, Conrad C, Di Nardo A, Homey B, Lauerma A, et al. Plasmacytoid dendritic cells sense skin injury and promote wound 
healing through type I interferons. J Exp Med. (2010) 207:2921-30. doi: $10.1084 /$ jem.20101102

14. Di Cesare A, Di Meglio P, Nestle FO. The IL-23/Th17 axis in the immunopathogenesis of psoriasis. J Invest Dermatol. (2009) 129:1339-50. doi: $10.1038 /$ jid. 2009.59

15. Tohyama M, Yang L, Hanakawa Y, Dai X, Shirakata Y, Sayama K. IFNalpha enhances IL-22 receptor expression in keratinocytes: a possible role in the development of psoriasis. J Invest Dermatol. (2012) 132:1933-5. doi: 10.1038/jid.2011.468

16. Lowes MA, Russell CB, Martin DA, Towne JE, Krueger JG. The IL-23/T17 pathogenic axis in psoriasis is amplified by keratinocyte responses. Trends Immunol. (2013) 34:174-81. doi: 10.1016/j.it.2012.11.005

17. Nestle FO, Kaplan DH, Barker J. Psoriasis. N Engl J Med. (2009) 361:496-509. doi: 10.1056/NEJMra0804595

18. Tzu J, Kerdel F. From conventional to cutting edge: the new era of biologics in treatment of psoriasis. Dermatol Ther. (2008) 21:131-41. doi: $10.1111 / j .1529-8019.2008 .00180 . x$

19. Dong J, Goldenberg G. New biologics in psoriasis: an update on IL-23 and IL-17 inhibitors. Cutis. (2017) 99:123-7.

20. Fotiadou C, Lazaridou E, Sotiriou E, Ioannides D. Targeting IL-23 in psoriasis: current perspectives. Psoriasis. (2018) 8:1-5. doi: 10.2147/PTT.S98893

21. Todke P, Shah VH. Psoriasis: implication to disease and therapeutic strategies, with an emphasis on drug delivery approaches. Int J Dermatol. (2018) 57:1387-402. doi: 10.1111/ijd.14047

22. Blauvelt A, Langley R, Szepietowski J, Sirgurgeirsson B, Tyring S, Messina I, et al. Secukinumab withdrawal leads to loss of treatment responses in a majority of subjects with plaque psoriasis with retreatment resulting in rapid regain of responses: a pooled analysis of two phase 3 trials. J. Am Acad Dermatol. (2016) 74:Ab273. doi: 10.1016/j.jaad.2016.02.1055

23. Khemis A, Cavalie M, Montaudie H, Lacour JP, Passeron T. Rebound pustular psoriasis after brodalumab discontinuation. Br J Dermatol. (2016) 175:1065-6. doi: 10.1111/bjd.14627

24. Papp KA, Reich K, Paul C, Blauvelt A, Baran W, Bolduc C, et al. A prospective phase III, randomized, double-blind, placebo-controlled study of brodalumab in patients with moderate-to-severe plaque psoriasis. Br J Dermatol. (2016) 175:273-86. doi: 10.1111/bjd.14493

25. Masson Regnault M, Konstantinou MP, Khemis A, Poulin Y, Bourcier M, Amelot F, et al. Early relapse of psoriasis after stopping brodalumab: a retrospective cohort study in 77 patients. J Eur Acad Dermatol Venereol. (2017) 31:1491-6. doi: 10.1111/jdv.14387

26. Lande R, Gregorio J, Facchinetti V, Chatterjee B, Wang YH, Homey B, et al. Plasmacytoid dendritic cells sense self-DNA coupled with antimicrobial peptide. Nature. (2007) 449:564-9. doi: 10.1038/nature06116

27. Albanesi C, Madonna S, Gisondi P, Girolomoni G. The interplay between keratinocytes and immune cells in the pathogenesis of psoriasis. Front Immunol. (2018) 9:1420. doi: 10.3389/fimmu.2018.01549

28. Li H, Yao Q, Mariscal AG, Wu X, Hulse J, Pedersen E, et al. Epigenetic control of IL-23 expression in keratinocytes is important for chronic skin inflammation. Nat Commun. (2018) 9:1420. doi: 10.1038/s41467-018-03704-z

29. Xu M, Lu H, Lee YH, Wu Y, Liu K, Shi Y, et al. An Interleukin25-mediated autoregulatory circuit in keratinocytes plays a pivotal role in psoriatic skin inflammation. Immunity. (2018) 48:787-98.e4. doi: 10.1016/j.immuni.2018.03.019

30. Lai Y, Di Nardo A, Nakatsuji T, Leichtle A, Yang Y, Cogen AL, et al. Commensal bacteria regulate Toll-like receptor 3-dependent inflammation after skin injury. Nat Med. (2009) 15:1377-82. doi: 10.1038/nm.2062

31. Bernard JJ, Cowing-Zitron C, Nakatsuji T, Muehleisen B, Muto J, Borkowski $\mathrm{AW}$, et al. Ultraviolet radiation damages self-noncoding RNA and is detected by TLR3. Nat Med. (2012) 18:1286-90. doi: 10.1038/nm.2861

32. Pasparakis M, Courtois G, Hafner M, Schmidt-Supprian M, Nenci A, Toksoy $\mathrm{A}$, et al. TNF-mediated inflammatory skin disease in mice with epidermisspecific deletion of IKK2. Nature. (2002) 417:861-6. doi: 10.1038/nature 00820

33. Zenz R, Eferl R, Kenner L, Florin L, Hummerich L, Mehic D, et al. Psoriasislike skin disease and arthritis caused by inducible epidermal deletion of Jun proteins. Nature. (2005) 437:369-75. doi: 10.1038/nature03963

34. Wolfram J, Diaconu D, Hatala D, Rastegar J, Knutsen D, Lowther A, et al. Keratinocyte but not endothelial cell-specific overexpression of Tie2 leads to the development of psoriasis. Am J Pathol. (2009). 174:1443-58. doi: 10.2353/ajpath.2009.080858

35. Johnston A, Fritz Y, Dawes SM, Diaconu D, Al-Attar PM, Guzman AM, et al. Keratinocyte overexpression of IL-17C promotes psoriasiform skin inflammation. J Immunol. (2013) 190:2252-62. doi: 10.4049/jimmunol.1201505

36. Sano S, Chan KS, Carbajal S, Clifford J, Peavey M, Kiguchi K, et al. Stat3 links activated keratinocytes and immunocytes required for development of psoriasis in a novel transgenic mouse model. Nat Med. (2005) 11:43-9. doi: $10.1038 / \mathrm{nm} 1162$

37. Matsumoto R, Dainichi T, Tsuchiya S, Nomura T, Kitoh A, Hayden MS, et al Epithelial TRAF6 drives IL-17-mediated psoriatic inflammation. Jci Insight. (2018) 3:121175. doi: 10.1172/jci.insight.121175

38. Crow MK, Olferiev M, Kirou KA. Type I interferons in autoimmune disease. Annu Rev Pathol. (2018) 14:369-3. doi: 10.1146/annurev-pathol-020117-043952

39. Trinchieri G. Type I interferon: friend or foe? J Exp Med. (2010) 207:2053-63. doi: $10.1084 /$ jem. 20101664

40. Theofilopoulos AN, Baccala R, Beutler B, Kono DH. Type I interferons (alpha/beta) in immunity and autoimmunity. Annu Rev Immunol. (2005) 23:307-36. doi: 10.1146/annurev.immunol.23.021704.115843

41. Stetson DB, Medzhitov R. Type I interferons in host defense. Immunity. (2006) 25:373-81. doi: 10.1016/j.immuni.2006.08.007

42. Banchereau J, Pascual V. Type I interferon in systemic lupus erythematosus and other autoimmune diseases. Immunity. (2006) 25:383-92. doi: 10.1016/j.immuni.2006.08.010

43. Pascual V, Farkas L, Banchereau J. Systemic lupus erythematosus: all roads lead to type I interferons. Curr Opin Immunol. (2006) 18:676-82. doi: 10.1016/j.coi.2006.09.014

44. Baechler EC, Bilgic H, Reed AM. Type I interferon pathway in adult and juvenile dermatomyositis. Arthritis Res Ther. (2011) 13:249. doi: $10.1186 /$ ar3531

45. Wu M, Assassi S. The role of type 1 interferon in systemic sclerosis. Front Immunol. (2013) 4:266. doi: 10.3389/fimmu.2013.00266

46. Yao $\mathrm{Y}$, Liu Z, Jallal B, Shen N, Ronnblom L. Type I interferons in Sjogren's syndrome. Autoimmun Rev. (2013) 12:558-66. doi: 10.1016/j.autrev.2012.10.006

47. Dorner T, Lipsky PE. Beyond pan-B-cell-directed therapy - new avenues and insights into the pathogenesis of SLE. Nat Rev Rheumatol. (2016) 12:645-57. doi: 10.1038/nrrheum.2016.158

48. Armstrong DL, Zidovetzki R, Alarcon-Riquelme ME, Tsao BP, Criswell LA, Kimberly RP, et al. GWAS identifies novel SLE susceptibility genes and explains the association of the HLA region. Genes Immun. (2014) 15:347-54. doi: 10.1038/gene.2014.23

49. Yamamoto T, Katayama I, Nishioka K. Psoriasis and hepatitis C virus. Acto Dermato Venereol. (1995) 75:482-3.

50. Erkek E, Karaduman A, Akcan Y, Sokmensuer C, Bukulmez G. Psoriasis associated with $\mathrm{HCV}$ and exacerbated by interferon alpha: complete clearance with acitretin during interferon alpha treatment for chronic active hepatitis. Dermatology. (2000) 201:179-81. doi: 10.1159/000018447

51. Funk J, Langeland T, Schrumpf E, Hanssen LE. Psoriasis induced by interferon-alpha. $\mathrm{Br} \quad \mathrm{J}$ Dermatol. (1991) 125:463-5. doi: 10.1111/j.1365-2133.1991.tb14774.x

52. Toussirot E, Bereau M, Bossert M, Malkoun I, Lohse A. Occurrence of psoriatic arthritis during interferon Beta 1a treatment for multiple sclerosis. Case Rep Rheumatol. (2014) 2014:949317. doi: 10.1155/2014/949317

53. Millan-Pascual J, Turpin-Fenoll L, Del Saz-Saucedo P, Rueda-Medina I, Navarro-Munoz S. Psoriasis during natalizumab treatment for multiple sclerosis. J Neurol. (2012) 259:2758-60. doi: 10.1007/s00415-012-6713-1

54. van der Fits L, van der Wel LI, Laman JD, Prens EP, Verschuren MCM. In psoriasis lesional skin the type I interferon signaling pathway is activated, whereas interferon- $\alpha$ sensitivity is unaltered. J Invest Dermatol. (2004) 122:5160. doi: 10.1046/j.0022-202X.2003.22113.x

55. Yao Y, Richman L, Morehouse C, de los Reyes M, Higgs BW, Boutrin A, et al. Type I interferon: potential therapeutic target for psoriasis? PLoS ONE. (2008) 3:e2737. doi: 10.1371/journal.pone.0002737

56. Baldwin HM, Pallas K, King V, Jamieson T, McKimmie CS, Nibbs RJ, et al. Microarray analyses demonstrate the involvement of type I interferons in 
psoriasiform pathology development in D6-deficient mice. J Biol Chem. (2013) 288:36473-83. doi: 10.1074/jbc.M113.491563

57. Gui J, Gober M, Yang X, Katlinski KV, Marshall CM, Sharma M, et al. Therapeutic elimination of the type 1 interferon receptor for treating psoriatic skin inflammation. J Invest Dermatol. (2016) 136:1990-2002. doi: 10.1016/j.jid.2016.06.608

58. Hida S, Ogasawara K, Sato K, Abe M, Takayanagi H, Yokochi T, et al. CD8(+) $\mathrm{T}$ cell-mediated skin disease in mice lacking IRF-2, the transcriptional attenuator of interferon-alpha/beta signaling. Immunity. (2000) 13:643-55. doi: 10.1016/S1074-7613(00)00064-9

59. Bielenberg DR, McCarty MF, Bucana CD, Yuspa SH, Morgan D, Arbeit $\mathrm{JM}$, et al. Expression of interferon-beta is associated with growth arrest of murine and human epidermal cells. J Invest Dermatol. (1999) 112:802-9. doi: 10.1046/j.1523-1747.1999.00566.x

60. Livden JK, Nilsen R, Bjerke JR, Matre R. In situ localization of interferons in psoriatic lesions. Arch Dermatol Res. (1989) 281:392-7. doi: 10.1007/BF00455323

61. Baccala R, Hoebe K, Kono DH, Beutler B, Theofilopoulos AN. TLRdependent and TLR-independent pathways of type I interferon induction in systemic autoimmunity. Nat Med. (2007) 13:543-51. doi: 10.1038/ nm1590

62. Ganguly D, Chamilos G, Lande R, Gregorio J, Meller S, Facchinetti $\mathrm{V}$, et al. Self-RNA-antimicrobial peptide complexes activate human dendritic cells through TLR7 and TLR8. J Exp Med. (2009) 206:1983-94. doi: 10.1084/jem.20090480

63. Shallev L, Kopel E, Feiglin A, Leichner GS, Avni D, Sidi Y, et al. Decreased Ato-I RNA editing as a source of keratinocytes' dsRNA in psoriasis. RNA. (2018) 24:828-40. doi: 10.1261/rna.064659.117

64. Bijlmakers MJ, Kanneganti SK, Barker JN, Trembath RC, Capon F. Functional analysis of the RNF114 psoriasis susceptibility gene implicates innate immune responses to double-stranded RNA in disease pathogenesis. Hum Mol Genet. (2011) 20:3129-37. doi: 10.1093/hmg/ddr215

65. Nelson AM, Reddy SK, Ratliff TS, Hossain MZ, Katseff AS, Zhu AS, et al. dsRNA released by tissue damage activates TLR3 to drive skin regeneration. Cell Stem Cell. (2015) 17:139-51. doi: 10.1016/j.stem.2015. 07.008
66. Takahashi T, Kulkarni NN, Lee EY, Zhang LJ, Wong GCL, Gallo RL. Cathelicidin promotes inflammation by enabling binding of selfRNA to cell surface scavenger receptors. Sci Rep. (2018) 8:4032. doi: 10.1038/s41598-018-22409-3

67. Ong PY, Ohtake T, Brandt C, Strickland I, Boguniewicz M, Ganz T, et al. Endogenous antimicrobial peptides and skin infections in atopic dermatitis. N Engl J Med. (2002) 347:1151-60. doi: 10.1056/NEJMoa021481

68. Lee EY, Takahashi T, Curk T, Dobnikar J, Gallo RL, Wong GCL. Crystallinity of double-stranded RNA-antimicrobial peptide complexes modulates tolllike receptor 3-mediated inflammation. ACS Nano. (2017) 11:12145-55. doi: 10.1021/acsnano.7b05234

69. Grine L, Dejager L, Libert C, Vandenbroucke RE. An inflammatory triangle in psoriasis: TNF, type I IFNs and IL-17. Cytokine Growth Factor Rev. (2015) 26:25-33. doi: 10.1016/j.cytogfr.2014.10.009

70. Palucka AK, Blanck JP, Bennett L, Pascual V, Banchereau J. Cross-regulation of TNF and IFN-alpha in autoimmune diseases. Proc Natl Acad Sci USA. (2005) 102:3372-7. doi: 10.1073/pnas.0408506102

71. Ju X, Zenke M, Hart DN, Clark GJ. CD300a/c regulate type I interferon and TNF-alpha secretion by human plasmacytoid dendritic cells stimulated with TLR7 and TLR9 ligands. Blood. (2008) 112:1184-94. doi: 10.1182/blood-2007-12-127951

72. Conrad C, Di Domizio J, Mylonas A, Belkhodja C, Demaria O, Navarini AA, et al. TNF blockade induces a dysregulated type I interferon response without autoimmunity in paradoxical psoriasis. Nat Commun. (2018) 9:25. doi: 10.1038/s41467-017-02466-4

Conflict of Interest Statement: The author declares that the research was conducted in the absence of any commercial or financial relationships that could be construed as a potential conflict of interest.

Copyright (c) 2019 Zhang. This is an open-access article distributed under the terms of the Creative Commons Attribution License (CC BY). The use, distribution or reproduction in other forums is permitted, provided the original author(s) and the copyright owner(s) are credited and that the original publication in this journal is cited, in accordance with accepted academic practice. No use, distribution or reproduction is permitted which does not comply with these terms. 